\title{
1,3,5-Triamino-2,4,6-trinitrobenzene and Magnesium Interaction-A DFT Treatment
}

\section{Lemi Türker}

Department of Chemistry, Middle East Technical University, Üniversiteler, Eskişehir Yolu No: 1, 06800 Çankaya/Ankara, Turkey; e-mail: 1turker@gmail.com; lturker@metu.edu.tr

\begin{abstract}
1,3,5-Triamino-2,4,6-trinitrobenzene, known as TATB, is an insensitive energetic material. On the other hand, certain metals like $\mathrm{Al}, \mathrm{Mg}$ etc., are often involved in formulation of certain ammunition to increase the heat output of the composite. In the present study, the interaction of TATB and magnesium is considered in TATB $+\mathrm{Mg}$ and $\mathrm{TATB}+2 \mathrm{Mg}$ composites within the constraints of density functional theory at the level of B3LYP/6-311++G(d,p). The magnesium component disturbs TATB molecule mainly conformationally without causing any bond rupture. The composite formation is favorable, exothermic and they are electronically stable. As the magnesium content increases, the composites become more sensitive to impulse stimulus. Certain physicochemical, quantum chemical and spectral data are collected and discussed.
\end{abstract}

\section{Introduction}

For an high explosive (HE), thermal stability is of main concern regarding to the formulation, processing, and handling but also vital for its safety in the cases of fuel fires, propellant fires, and even including a potential for sympathetic detonation. It has been long known that 1,3,5-triamino-2,4,6-trinitrobenzene, abbreviated as TATB, is a reasonably powerful high explosive possessing thermal and shock stability which is considerably greater than that of any other known material of comparable energy. It is extremely insensitive to shock, vibration, fire, or impact. Because it is so difficult to detonate by accident, even under severe conditions, it has become preferred high

Received: November 10, 2020; Accepted: December 14, 2020

Keywords and phrases: 1,3,5-triamino-2,4,6-trinitrobenzene, TATB, explosives, magnesium, DFT, NICS.

Copyright (C) 2021 Lemi Türker. This is an open access article distributed under the Creative Commons Attribution License, which permits unrestricted use, distribution, and reproduction in any medium, provided the original work is properly cited. 
explosive for applications where extreme safety is required, such as the explosives used in nuclear weapons, where accidental detonation during an airplane crash or rocket misfiring would present extreme dangers. TATB was obtained years ago by Jacson and Wing by displacing bromines from structure of 1,3,5-tribromo-2,4,6-trinitrobenzene with cold alcoholic solution of ammonia [1,2]. The compound TATB has been known for its unusual thermal properties since the $1950 \mathrm{~s}$. TATB decomposes at $360^{\circ} \mathrm{C}$ without melting [3]. It is a yellow-brown crystalline solid that is insoluble in most solvents. The best solvent is hot, concentrated sulfuric acid. TATB decomposes rapidly just below the melting point, however it has excellent thermal stability in the range $260-290^{\circ} \mathrm{C}$, which represents the upper temperature limit at which it may be used. In the years following II world war, research focused intensely on some high energetic materials in order to synthesize much safer and more heat resistant explosives [4]. One of the molecules fulfilling those criteria was TATB. The striking features of it is the strong and extensive hydrogen bonding (both inter- and intramolecular types) between $\mathrm{NO}_{2}$ and $\mathrm{NH}_{2}$ groups present $[5,6]$. Those electron acceptor and donor groups in the structure contribute its stability. The first important work in order to enlighten this unique stability was done in 1965 by Cady and Larson, who managed to determine the crystal structure of TATB [5]. Since then intense research has been published on TATB [7-20] which includes not only the experimental studies, but various computational work on TATB as well [21-26].

In the present work, the interaction of TATB and magnesium are investigated quantum chemically within the limitations of density functional theory (DFT) at the levels of B3LYP/6-311++G(d,p) level.

\section{Method of Calculation}

In the present study, firstly the initial structural optimizations of all the structures leading to energy minima have been achieved by using MM2 method followed by semiempirical PM3 self-consistent fields molecular orbital (SCF MO) method [27, 28] at the restricted level $[29,30]$. The subsequent optimizations were achieved at Hartree-Fock level using various basis sets hierarchically. Then, the structural optimizations were managed within the framework of density functional theory (DFT) [31, 32] at the levels of and B3LYP/6-311++G(d,p) [30, 33]. The exchange term of B3LYP consists of hybrid Hartree-Fock and local spin density (LSD) exchange functions with Becke's gradient correlation to LSD exchange $[32,34]$. The correlation term of B3LYP consists of the Vosko, Wilk, Nusair (VWN3) local correlation functional [35] and Lee, Yang, Parr 
(LYP) correlation correction functional [36]. Additionally, the vibrational analyses have been done. The total electronic energies are corrected for the zero point vibrational energy (ZPE). The normal mode analysis for each structure yielded no imaginary frequencies for the $3 \mathrm{~N}-6$ vibrational degrees of freedom, where $N$ is the number of atoms in the system. This indicates that the structure of each molecule corresponds to at least a local minimum on the potential energy surface. All these calculations were done by using the Spartan 06 package program [37].

For NICS data, the absolute NMR shielding values [38] were calculated by employing the Gauge-Independent Atomic Orbital method [39] with the restricted closed shell formalism at the level of B3LYP/6-311++G(d,p). The NICS values were collected by calculating absolute NMR shielding values at the ring centers, NICS (0). The NICS (0) calculations of the present systems were performed by the use of the Gaussian 03 package program [40].

\section{Results and Discussion}

TATB molecule possesses structures $\mathbf{A}$ and $\mathbf{B}$ as its two resonance forms. They have aromatic benzene ring and not-aromatic hexagonal ring, respectively. In the later case the nitro and amino substituents have exocyclic carbon-nitrogen double bonds. Structure-B is an interesting, highly charge separated resonance form originated from structure-A.
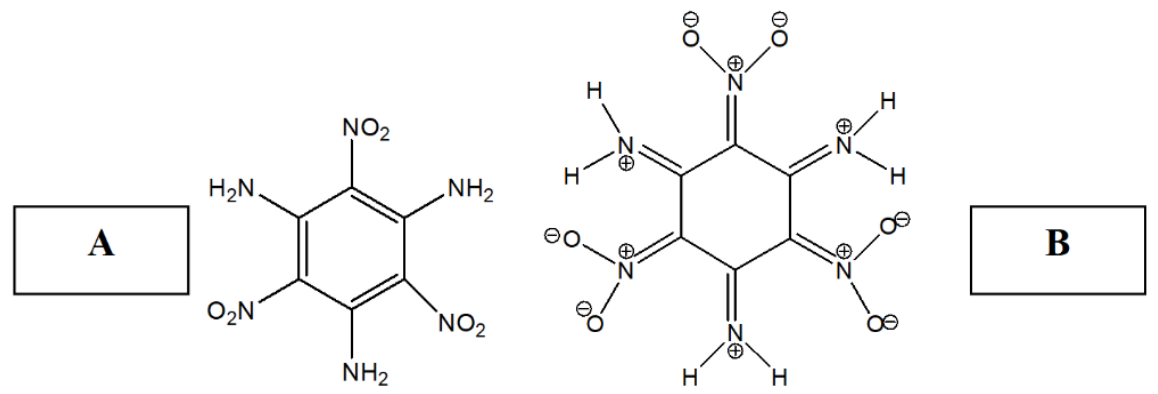

Omelchenko et al., studied geometrical parameters, aromaticity, and conformational flexibility of the set of polysubstituted benzenes with different number and position of nitro and amino groups [22] and concluded that the presence of nitro and amino groups in vicinal positions formed strong intramolecular resonance-assisted hydrogen bonds. Also they studied TATB molecule, which possesses alternatingly substituted nitro and amino groups and should have strong intramolecular resonance-assisted hydrogen bonds.

In the present study, $\mathrm{TATB}+\mathrm{Mg}$ and $\mathrm{TATB}+2 \mathrm{Mg}$ composites have been considered 
which have the magnesium contents of 8.6 and $15.8 \%$, respectively. In the present treatment, they have been respectively labeled as I and II. Figure 1 shows the optimized structures as well as the direction of the dipole moments of TATB and its magnesium composites considered.
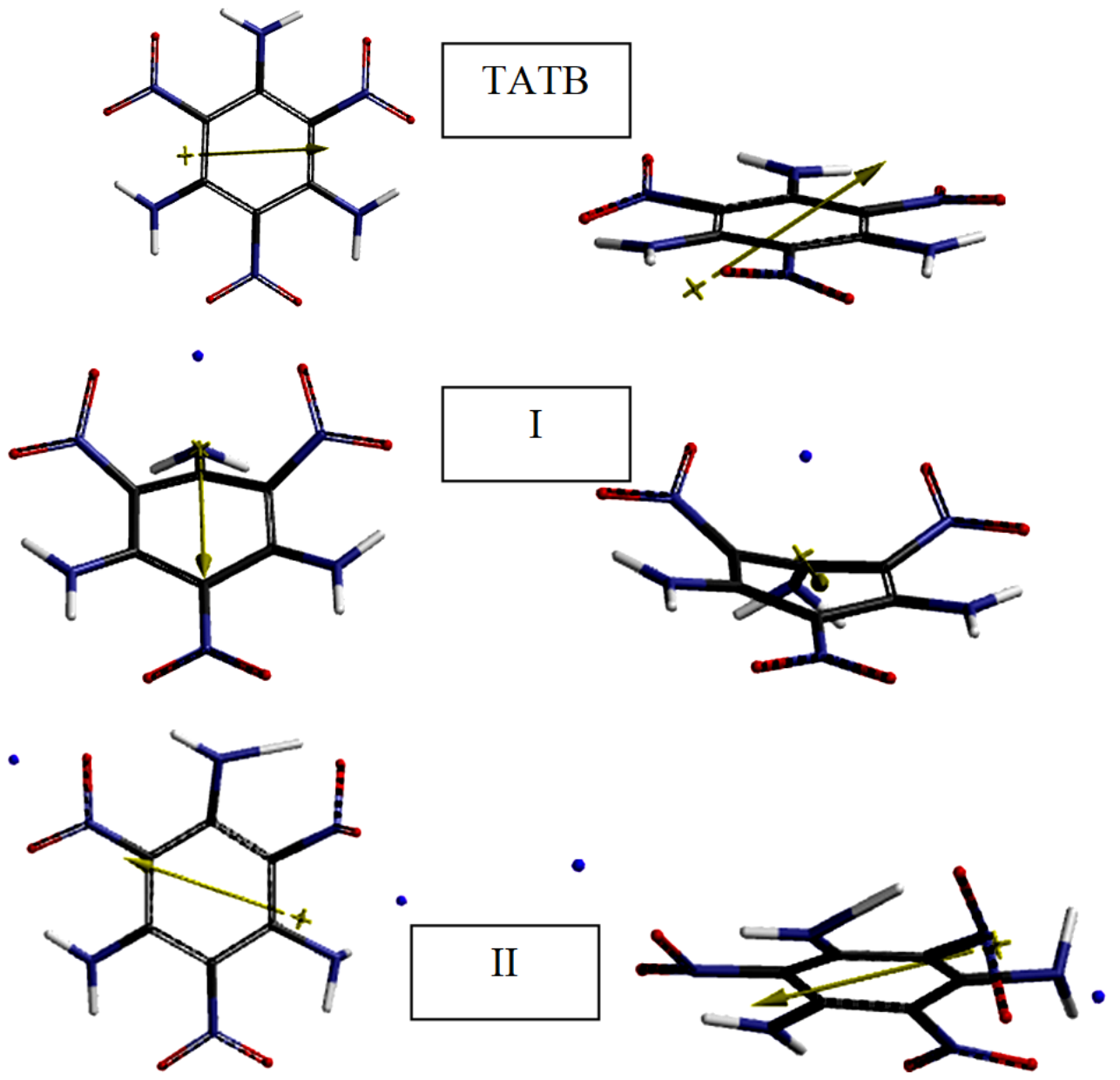

Figure 1. Optimized structures of TATB and the composites considered (From different angle of views).

Figure 2 shows the calculated bond lengths in the composites considered. Note that in structure-II one of N-H bonds is longer (1.69 $\AA$ ) than the other(s) which is hydrogen bond donor to the adjacent nitro group. 


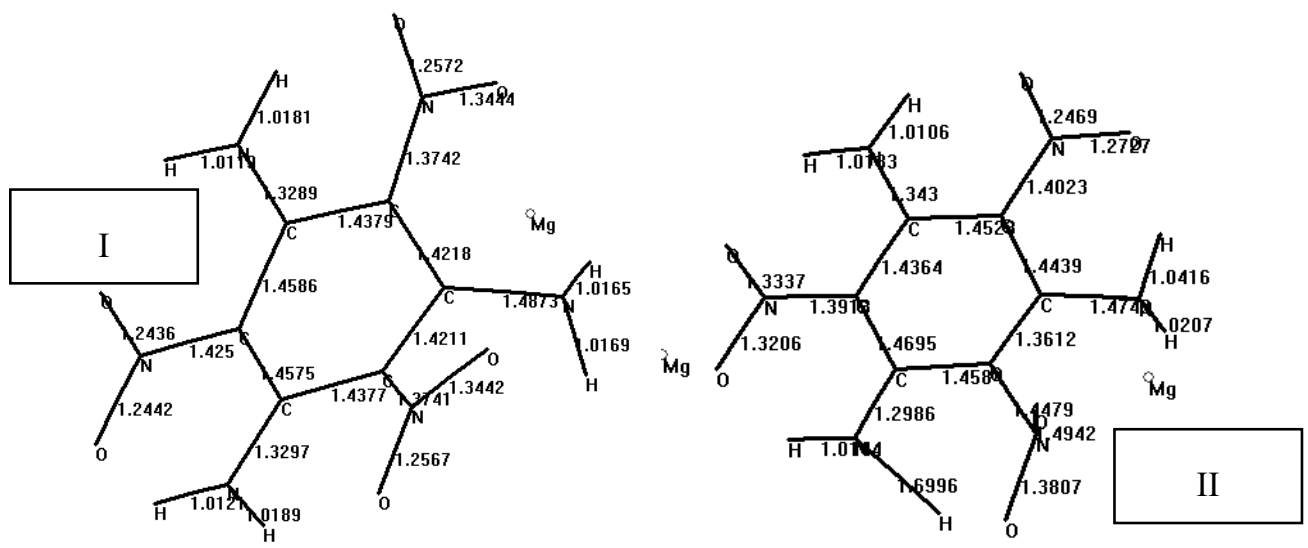

Figure 2. The calculated bond lengths $(\AA)$ in the composites considered.

Figure 3 shows the calculated IR spectra of TATB and the composite structures considered. The N-H stretchings happen in the region around $3500 \mathrm{~cm}^{-1}$. In structure-II an asymmetrical N-H stretching occurs at $3070 \mathrm{~cm}^{-1}$ which is absent in the spectrum of TATB and structure-I.
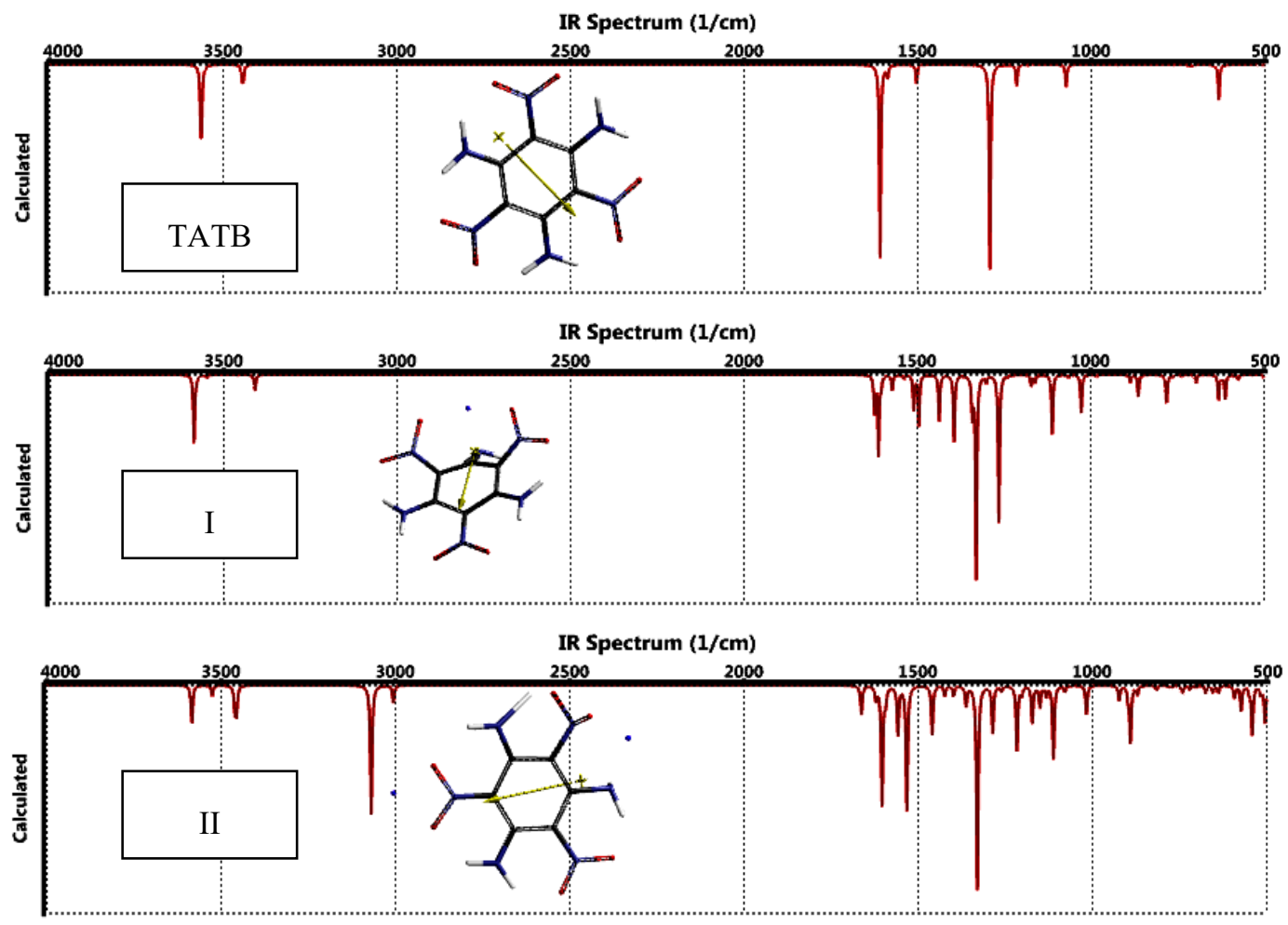

Figure 3. Calculated IR spectra of the structures considered. 
Table 1 presents some properties of the structures considered. Note that composite-II has greater dipole moment and polarizability values compared to composite-I.

Table 1. Some properties of the composite structures considered.

\begin{tabular}{cccccc}
\hline Structure & $\begin{array}{c}\text { Area } \\
\left(\AA^{2}\right)\end{array}$ & $\begin{array}{c}\text { Volume } \\
\left(\AA^{3}\right)\end{array}$ & Ovality & $\begin{array}{c}\text { Dipole } \\
(\text { Debye })\end{array}$ & Polarizability \\
\hline I & 221.08 & 198.31 & 1.34 & 4.95 & 56.98 \\
II & 234.48 & 208.06 & 1.38 & 6.35 & 58.15 \\
\hline
\end{tabular}

Table 2 lists some energies of the composite structures considered where E, ZPE and $E_{C}$ stand for the total electronic energy, zero point vibrational energy and the corrected total electronic energy, respectively. The data reveal that the composites are electronically stable.

Table 2. Some energies of the composite structures considered.

\begin{tabular}{cccc}
\hline Structure & $\mathbf{E}$ & $\mathbf{Z P E}$ & $\mathbf{E}_{\mathbf{C}}$ \\
\hline I & -3182795.81 & 414.90 & -3182380.91 \\
II & -3708080.34 & 413.65 & -3707666.69 \\
\hline
\end{tabular}

Energies in $\mathrm{kJ} / \mathrm{mol}$.

Table 3 tabulates some of the thermodynamic values of the composite structures considered. According to the data the composites are exothermic and their formations are favorable.

Table 3. Some thermodynamic values of the structures considered.

\begin{tabular}{cccc}
\hline Structure & $\mathbf{H}^{\mathbf{o}}(\mathbf{k J} / \mathbf{m o l})$ & $\mathbf{S}^{\mathbf{0}}\left(\mathbf{J} / \mathbf{m o l}^{\mathbf{0}}\right)$ & $\mathbf{G}^{\mathbf{0}}(\mathbf{k J} / \mathbf{m o l})$ \\
\hline I & -3182370.544 & 483.71 & -3182370.544 \\
II & -3707658.133 & 507.85 & -3707658.133 \\
\hline
\end{tabular}

Figure 4 shows the electrostatic potential charges (ESP) on the atoms of the structure optimized composites systems considered. Note that the ESP charges are obtained by the program based on a numerical method that generates charges that reproduce the electrostatic potential field from the entire wavefunction [37]. 

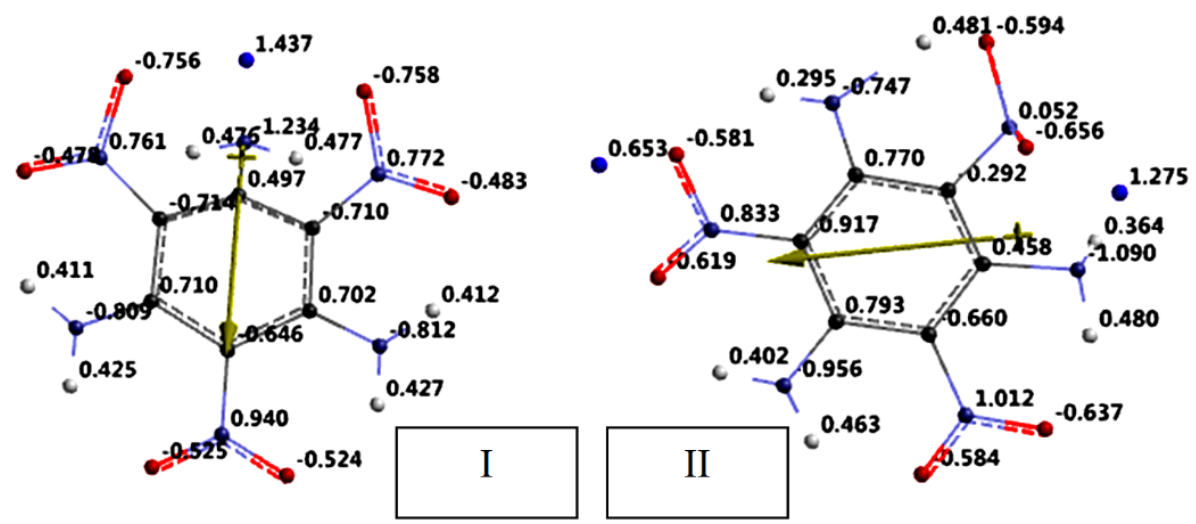

Figure 4. Electrostatic potential charges (ESP) of the composites.

In both of the cases the magnesium atoms possess some positive charge accumulation. The loading of the second magnesium atom causes the first one to have less positive charge as compared to the previous case. Also positive charge development of the second one is less than the first magnesium atom. Note that locations of the magnesium atoms in structure-II are next to $\mathrm{NH}_{2}$ and $\mathrm{NO}_{2}$ groups, respectively. Also note that the direction of the dipole moment is from somewhere around that $\mathrm{NH}_{2}$ group to that of $\mathrm{NO}_{2}$ group mentioned.

Appearance of the electrostatic potential maps of the systems is shown in Figure 5 where red/reddish and blue/ green regions stand for negative and positive potential fields, respectively. It gives some idea about which $\mathrm{NH}_{2}$ group(s) donates electron population at what extents and which $\mathrm{NO}_{2}$ group(s) accepts.
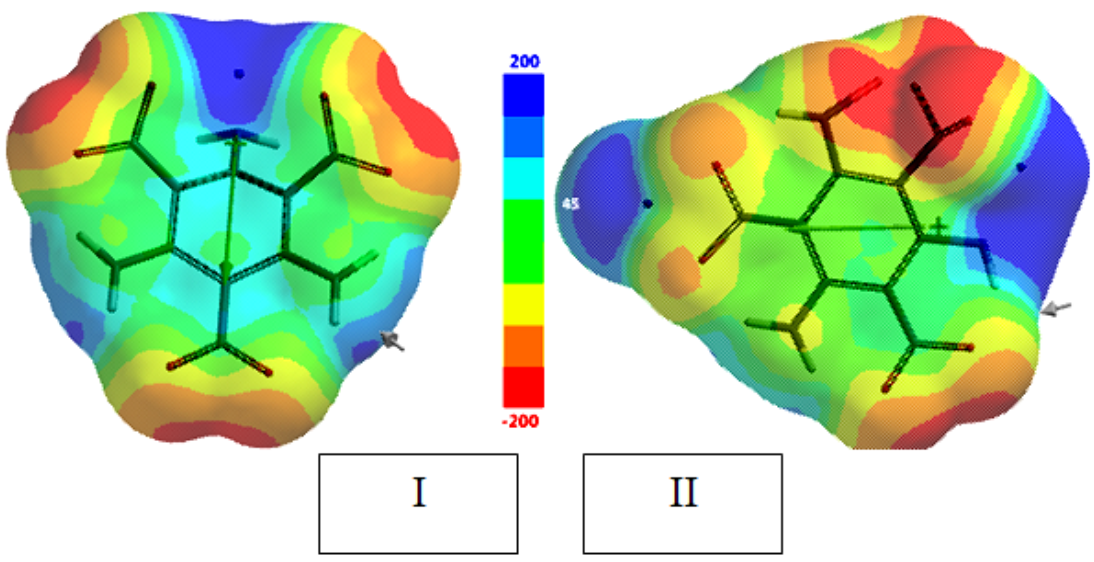

Figure 5. Electrostatic potential maps of the composites. 
Table 4 shows the HOMO, LUMO energies and the interfrontier molecular orbital energy gap $(\Delta \varepsilon)$ values of the systems considered. As seen from the table magnesium atom(s) raises both the HOMO and LUMO energy levels of composite-I as compared to TATB case. Whereas in composite-II the HOMO level raises but the LUMO lowers down in the presence of magnesium atoms as compared to TATB case. Note that composite-II has higher HOMO but lower LUMO energy level as compared to composite-I. It means that the roles of two magnesium atoms are not the same in composite-II (see Figure 6 below).

On the other hand, presence of magnesium atoms decreases the HOMO-LUMO energy gap (interfrontier molecular orbital gap) more and more as its content increases. The narrowing of interfrontier molecular orbital (FMO) gap indicates that the composite should be more sensitive to impact stimuli because $\Delta \varepsilon$ values are related to impact sensitivity in explosives [41, 42]. Namely, as the FMO energy gap $(\Delta \varepsilon)$ becomes less and less the impact sensitivity increases more and more.

Table 4. The HOMO, LUMO energies and $\Delta \varepsilon$ values of the structures considered.

\begin{tabular}{lccc}
\hline Structure & HOMO & LUMO & $\Delta \varepsilon$ \\
\hline TATB & -736.81 & -320.83 & 415.98 \\
I & -467.13 & -269.08 & 198.05 \\
II & -423.21 & -377.66 & 45.55 \\
\hline
\end{tabular}

Energies in $\mathrm{kJ} / \mathrm{mol}$.

Figure 6 shows the HOMO and LUMO patters of the structures considered. TATB seems to have $\pi$-symmetry whereas the composites have lost it somewhat. In composite-I the magnesium atom contributes very little in to the LUMO. In composite-II one of the $\mathrm{Mg}$ atoms ( $\mathrm{Mg} 2$ in the figure) does not contribute in to the HOMO whereas the other one (Mg1) contributes almost nil to the LUMO.

Figure 7 shows the time-dependent density functional (TDDFT) UV-VIS spectra of the systems of present concern. The spectrum of TATB is very symmetrical having only one $\lambda_{\max }$ value. The figure also indicates that incorporation of magnesium shifts the spectrum of TATB to visible region more and more as the metal content increases. It is consistent with $\Delta \varepsilon$ values in Table 4 . That is as the interfrontier molecular orbital energy gap values $(\Delta \varepsilon)$ decrease bathochromic effect happens more profoundingly. The 
magnesium atom(s) disturbs the structure of TATB mainly conformationally without causing any bond cleavage. Meantime, various chromophoric moieties having different conjugation possibilities arise. Then, various electronic transitions occur to yield more than one $\lambda_{\max }$ values to appear in the spectra of the composites.
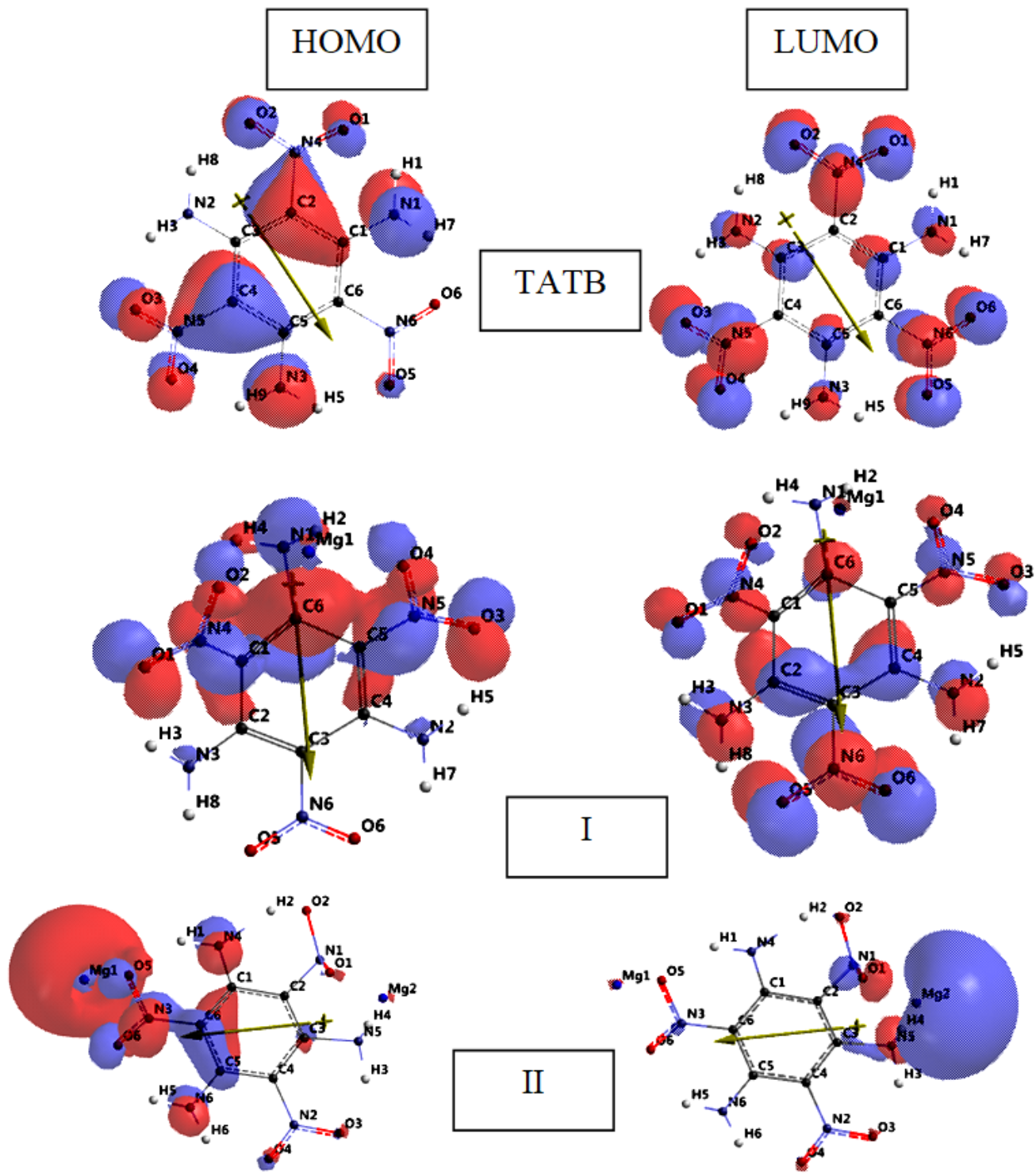

Figure 6. The HOMO and LUMO patterns of TATB and the composites. 

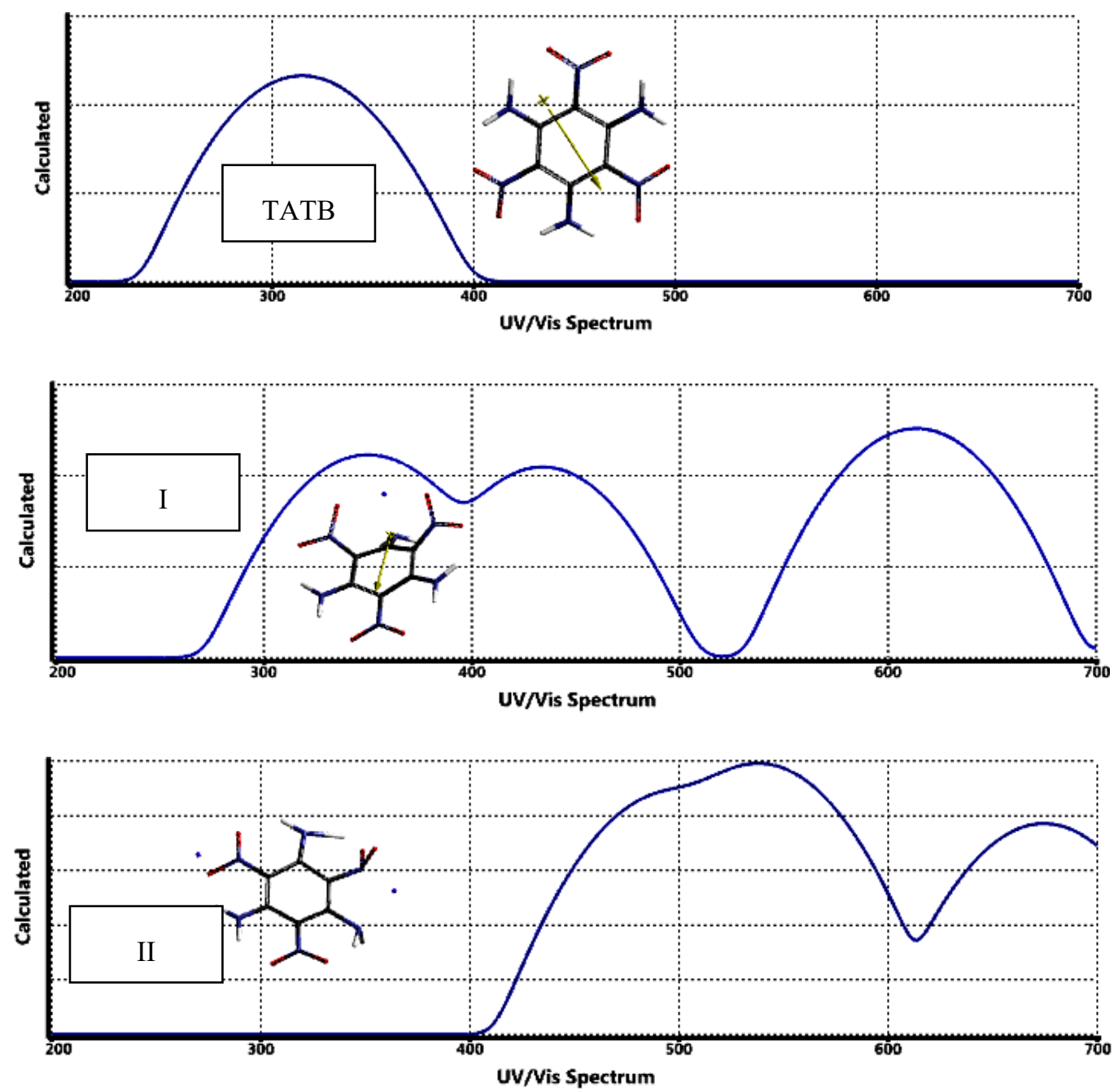

Figure 7. Calculated UV-VIS spectra of the structures considered.

Figure 8 shows the local ionization maps of the structures considered. In the local ionization potential map conventionally red regions on the density surface indicate areas from which electron removal is relatively easy, meaning that they are subject to electrophilic attack. On the other hand, regions having blue color represent areas where ionization is relatively difficult. Note that the red region in the case of structure-II locates nearby the magnesium atom which is next to the nitro group, whereas one of the blue region coincides on one of the $\mathrm{NH}_{2}$ groups such that both regions lie in the direction of the dipole moment vector. 


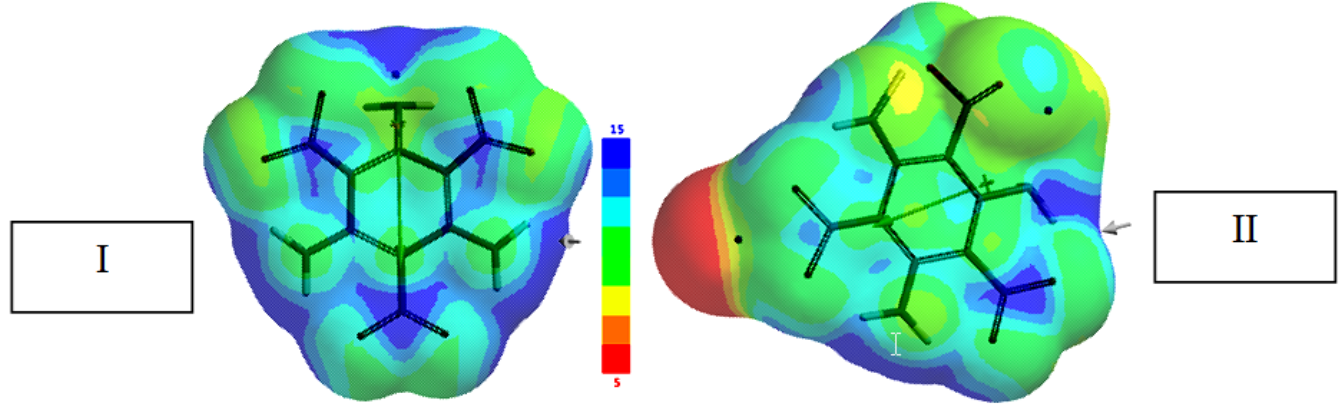

Figure 8. The local ionization potential maps of the structures considered.

Figure 9 shows the LUMO maps of the systems. A LUMO map displays the absolute value of the LUMO on the electron density surface. The blue color stands for the maximum value of the LUMO and the color red, the minimum value. Hence, a nucleophile attacks on the atom having the blue color.
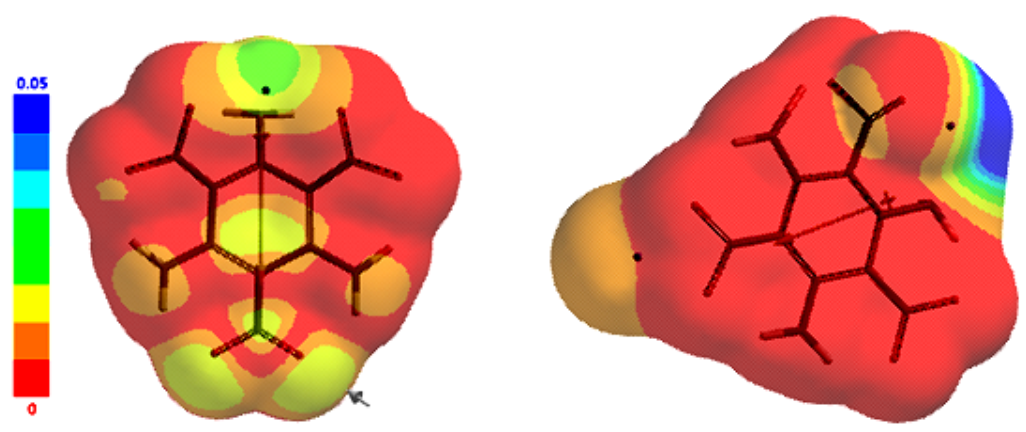

Figure 9. The LUMO maps of the structures considered.

\section{NICS}

A combination of various properties in cyclic delocalized systems dictates aromaticity. In general, aromaticity is discussed in terms of energetic, structural and magnetic criteria [43-49]. Schleyer introduced a simple and efficient probe for aromaticity that is "nucleus-independent chemical shift" (NICS) [49]. It is the computed value of the negative magnetic shielding at some selected point in space such as at a ring or cage center. The data calculated and piled in the literature indicate that negative NICS values denote aromaticity (e.g., -11.5 for benzene, -11.4 for naphthalene) whereas positive NICS values denote antiaromaticity (28.8 for cyclobutadiene) while small NICS values are indicative of non-aromaticity ( -2.1 for cyclohexane, -1.1 for adamantane). 
Presently, the NICS values of TATB, TATB $+\mathrm{Mg}$ and TATB $+2 \mathrm{Mg}$ are -5.9888 , -5.1804 and -4.2191 , respectively. According to the data aromaticity of the ring decreases as the magnesium content of the composite increases. Note that aromaticity of the ring in TATB is rather low which could be explained (in the framework of valence bond theory) by referring the contribution of resonance structure-B like, charge separated structures which perturb the ring current essential for aromaticity.

\section{Conclusion}

The present study, performed within the restrictions of density functional theory has revealed that TATB and magnesium are compatible with each other up to $15 \% \mathrm{Mg}$ content (present domain). However, magnesium somewhat perturbs TATB molecule by transferring some electron population to the organic component, acquiring some positive charge itself. Thus some properties of TATB molecule changes. The frontier molecular orbital energy gap narrows in the composites which should cause to arise systems more susceptible to impulse stimulus compared to TATB.

\section{References}

[1] C.L. Jacson and J.F. Wing, On tribromonitrobenzol (LIX), J. Am. Chem. Soc. 10 (1888), 283.

[2] C.L. Jacson and J.F. Wing, On the action of nitric acid on symmetrical trichlorobenzene (LIII), J. Am. Chem. Soc. 10 (1887), 348.

[3] R. Meyer, J. Köhler and A. Homburg, Explosives, Weinheim: Wiley-VCH, 2002.

[4] F. Taylor, Jr., Synthesis of new high energy explosives (II), derivatives of 1,3,5-tribromo2,4,6-trinitrobenzene, US Naval Ordnance Laboratory report, NAVORD 4405 (1956).

[5] H. Cady and A.C. Larson, The crystal structure of 1,3,5-triamino,-2,4,6-trinitrobenzene, Acta Cryst. 18 (1965), 485-496. https://doi.org/10.1107/S0365110X6500107X

[6] W.M. Trott and A.M. Renlund, Single-pulse Raman scattering study of triaminotrinitrobenzene under shock compression, J. Phys. Chem. 92 (21) (1988), 59215925. https://doi.org/10.1021/j100332a015

[7] V.D. Gupta and B.L. Deopura, Low-frequency neutron spectrum of 1,3,5-triamino-2,4,6trinitrobenzene, Mol. Phys. 19 (1970), 589-592.

https://doi.org/10.1080/00268977000101621 
[8] B.L. Deopura and V.D. Gupta, Vibration spectra of 1,3,5-triamino-2,4,6-trinitrobenzene, J. Chem. Phys. 54 (1970), 4013-4019. https://doi.org/10.1063/1.1675458

[9] J.R. Kolb and H.F. Rizzo, Growth of 1,3,5-triamino-2,4,6,-trinitrobenzene(TATB) 1, Prop. Exp. Pyrotech. 4 (1979), 10-16. https://doi.org/10.1002/prep.19810060202

[10] A.D. Britt, W.B. Moniz, G.C. Chingas, D.W. Moore, C.A. Heller and C.L. Ko, Free radicals of TATB, Prop. Exp. Pyrotech. 6 (1981), 94-95. https://doi.org/10.1002/prep.19810060403

[11] T.G. Towns, Vibrational spectrum of 1,3,5-triamino-2,4,6-trinitrobenzene, Spectrochim. Acta A 39 (1983), 801-804. https://doi.org/10.1016/0584-8539(83)80020-8

[12] M. Farber and R.D. Srivastava, Thermal decomposition of TATB, Combustion and Flame 42 (1981), 165-171. https://doi.org/10.1016/0010-2180(81)90155-3

[13] J. Sharma, W.L. Garrett, F.J. Owens and V.L. Vogel, X-Ray photoelectron study of electronic structure and ultraviolet and isothermal decomposition of TATB, J. Phys. Chem. 86 (1982), 1657-1661. https://doi.org/10.1021/j100206a034

[14] E. Catalano and P. Crawford, An enthalpic study of the thermal decomposition of TATB, Thermochim. Acta 61 (1983), 23-36. https://doi.org/10.1016/0040- 6031(83)80301-3

[15] P.C. Harihan, W.S. Koski, J.J. Kaufman and R.S. Miller, Ab initio MODPOT/VRDDO/MERGE calculations on energetic compounds, iii. nitroexplosives: polyaminopolynitrobenzenes (Including DATD, TATB, and Tetryl), Int. J. Quant. Chem. 23 (1983), 1493-1504. https://doi.org/10.1002/qua.560230431

[16] A.J. Davidson, R.P. Dias, D.M. Dattelbaum and C.S. Yoo, "Stubborn" triaminotrinitrobenzene: unusually high chemical stability of a molecular solid to 150 GPa, J. Chem. Phys. 135 (2011), 174507/1-174507/5. https://doi.org/10.1063/1.3658385.

[17] D.A. Tariq, The reactants equation of state for the tri-amino-tri-nitro-benzene (TATB) based explosive PBX 9502, J. Applied Physics 122 (2017), 035902/1-035902/8. https://doi.org/10.1063/1.498938.

[18] L.L. Stevens, N. Velisavljevic, D.E. Hooks and D.M. Dattelbaum, Hydrostatic compression curve for triamino-trinitrobenzene determined to 13.0 GPa with powder XRay diffraction, Prop. Explos. Pyrotech. 30(4) (2008), 286-295.

https://doi.org/10.1002/prep.200700270

[19] W. Yu, T. Zhang, J. Zuo, Y. Huang, G. Li, C. Han, J. Li and H. Huang, Effect of microwave irradiation on TATB explosive (II): Temperature response and other risk, $J$. Hazardous Materials 173(1-3) (2010), 249-252.

https://doi.org/10.1016/j.jhazmat.2009.07.152 
[20] W. Li Yuan, G.H. Tao, L. Zhang, Z. Zhang, Y. Xue, L. He, J. Huang and W. Yu, Super impact stable TATB explosives recrystallized by bicarbonate ionic liquids with a record solubility, Sci. Rep. 10 (2020), 4477. https://doi.org/10.1038/s41598-020-61470-9

[21] M.R. Manaa and L.E. Fried, Internal rotation in energetic systems: TATB, J. Phys. Chem. A 105 (27) (2001), 6765-6768. https://doi.org/10.1021/jp010890k

[22] I.V. Omelchenko, O.V. Shishkin, L. Gorb, F. Hill and J. Leszczynski, Properties, aromaticity, and substituents effects in poly nitro- and amino-substituted benzenes, Struct. Chem. 23 (2012), 1585-1597. https://doi.org/10.1007/s11224-012-9971-8

[23] C. Zhang, X. Cao and B. Xiang, Sandwich complex of TATB/Graphene: An approach to molecular monolayers of explosives, J. Phys. Chem. C 114 (51) (2010), 22684-22687. https://doi.org/10.1021/jp1104505

[24] R.S. Patil, S. Radhakrishnan, P.M. Jadhav, V.D. Ghule and T. Soman, Quantumchemical studies on TATB processes, Journal of Energetic Materials 28(2) (2010), 98113. https://doi.org/10.1080/07370650903222569

[25] R. Ahmadi, Study of thermodynamic parameters of (TATB) and its fullerene derivatives with different number of Carbon (C20, C24, C60), in different conditions of temperature, using density functional theory, Int. J. Nano Dimens. 8 (3) (2017), 250-256.

[26] L. Türker, Interaction of TATB with $\mathrm{Cu}$ and $\mathrm{Cu}^{+1}$. A DFT study, Defence Technology 15(1) (2019), 27-37. https://doi.org/10.1016/j.dt.2018.05.001

[27] J.J.P. Stewart, Optimization of parameters for semiempirical methods I. Method, $J$. Comput. Chem. 10 (1989), 209-220. https://doi.org/10.1002/jcc.540100208

[28] J.J.P. Stewart, Optimization of parameters for semi empirical methods II. Application, $J$. Comput. Chem. 10 (1989), 221-264. https://doi.org/10.1002/jcc.540100209

[29] A.R. Leach, Molecular Modeling, Essex: Longman, 1997.

[30] P. Fletcher, Practical Methods of Optimization, New York: Wiley, 1990.

[31] W. Kohn and L. Sham, Self-consistent equations including exchange and correlation effects, J. Phys. Rev.140 (1965), 1133-1138. https://doi.org/10.1103/PhysRev.140.A1133

[32] R.G. Parr and W. Yang, Density Functional Theory of Atoms and Molecules, London: Oxford University Press, 1989.

[33] C.J. Cramer, Essentials of Computational Chemistry, Chichester, West Sussex: Wiley, 2004.

[34] A.D. Becke, Density-functional exchange-energy approximation with correct asymptotic behavior, Phys. Rev. A 38 (1988), 3098-3100. https://doi.org/10.1103/PhysRevA.38.3098 
[35] S.H. Vosko, L. Wilk and M. Nusair, Accurate spin-dependent electron liquid correlation energies for local spin density calculations: a critical analysis, Can. J. Phys. 58 (1980), 1200-1211. https://doi.org/10.1139/p80-159

[36] C. Lee, W. Yang and R.G. Parr, Development of the Colle-Salvetti correlation-energy formula into a functional of the electron density, Phys. Rev. B 37 (1988), 785-789. https://doi.org/10.1103/PhysRevB.37.785

[37] SPARTAN 06, Wavefunction Inc., Irvine CA, USA, 2006.

[38] P. Pulay, J. F. Hinton and K. Wolinski, Efficient implementation of the GIAO method for magnetic properties: theory and application, in: Tossell J.A. (eds.), Nuclear Magnetic Shieldings and Molecular Structure, NATO ASI Series (Series C: Mathematical and Physical Sciences), 386, pp. 243-262, Dordrecht: Springer, 1993.

https://doi.org/10.1007/978-94-011-1652-7_12

[39] W.J. Hehre, L. Radom, P.R. van Schleyer and J.A. Pople, Ab Initio Molecular Orbital Theory, New York: Wiley, 1986.

[40] M.J. Frisch, G.W. Trucks, H.B. Schlegel, G.E. Scuseria, M.A. Robb, J.R. Cheeseman, J.A. Montgomery, Jr., T. Vreven, K.N. Kudin, J.C. Burant, J. M. Millam, S. S. Iyengar, J. Tomasi, V. Barone, B. Mennucci, M. Cossi, G. Scalmani, N. Rega, G.A. Petersson, H. Nakatsuji, M. Hada, M. Ehara, K. Toyota, R. Fukuda, J. Hasegawa, M. Ishida, T. Nakajima, Y. Honda, O. Kitao, H. Nakai, M. Klene, X. Li, J. E. Knox, H. P. Hratchian, J. B. Cross, V. Bakken, C. Adamo, J. Jaramillo, R. Gomperts, R.E. Stratmann, O. Yazyev, A.J. Austin, R. Cammi, C. Pomelli, J.W. Ochterski, P.Y. Ayala, K. Morokuma, G.A. Voth, P. Salvador, J.J. Dannenberg, V.G. Zakrzewski, S. Dapprich, A.D. Daniels, M.C. Strain, O. Farkas, D.K. Malick, A.D. Rabuck, K. Raghavachari, J.B. Foresman, J.V. Ortiz, Q. Cui, A.G. Baboul, S. Clifford, J. Cioslowski, B.B. Stefanov, G. Liu, A. Liashenko, P. Piskorz, I. Komaromi, R.L. Martin, D.J. Fox, T. Keith, M.A. Al-Laham, C.Y. Peng, A. Nanayakkara, M. Challacombe, P.M. W. Gill, B. Johnson, W. Chen, M.W. Wong, C. Gonzalez and J.A. Pople, Gaussian, Inc., Wallingford CT, 2004.

[41] V. Anbu, K.A. Vijayalakshmi, R. Karunathan, A.D. Stephen and P.V. Nidhin, Explosives properties of high energetic trinitrophenyl nitramide molecules: A DFT and AIM analysis, Arabian Journal of Chemistry 12(5) (2019), 621-632.

https://doi.org/10.1016/j.arabjc.2016.09.023

[42] N.R. Badders, C. Wei, A.A. Aldeeb, W.J. Rogers and M.S. Mannan, Predicting the impact sensitivities of polynitro compounds using quantum chemical descriptors, Journal of Energetic Materials 24 (2006), 17-33. https://doi.org/10.1080/07370650500374326

[43] V.I. Minkin, M.N. Glukhovtsev and B.Y. Simkin, Aromaticity and Antiaromaticity: Electronic and Structural Aspects, New York: Wiley, 1994. 
[44] P.R. Schleyer and H. Jiao, Introduction: aromaticity, Pure Appl. Chem. 68 (1996), 209218. http://dx.doi.org/10.1351/pac199668020209

[45] M.N. Glukhovtsev, Aromaticity today: Energetic and structural criteria. J. Chem. Educ. 74 (1997), 132-136. https://doi.org/10.1021/ed074p132

[46] T.M. Krygowski, M.K. Cyranski, Z. Czarnocki, G. Hafelinger and A.R. Katritzky, Aromaticity: A theoretical concept of immense practical importance, Tetrahedron 56 (2000), 1783-1796. https://doi.org/10.1016/S0040-4020(99)00979-5

[47] P.R. Schleyer, Introduction: Aromaticity, Chem. Rev. 101 (2001), 1115-1118. https://doi.org/10.1021/cr0103221

[48] M.K. Cyranski, T.M. Krygowski, A.R. Katritzky and P.R. Schleyer, To what extent can aromaticity be defined uniquely?, J. Org. Chem. 67 (2002), 1333-1338. https://doi.org/10.1021/jo016255s

[49] P.R. Schleyer, C. Maerker, A. Dransfeld, H. Jiao and N.J.R.E. Hommes, Nucleusindependent chemical shifts: A simple and efficient aromaticity probe, J. Am. Chem. Soc. 118 (1996), 6317-6318. https://doi.org/10.1021/ja960582d 